DOI 10.37882/2500-3682.2020.12.02

\title{
ПСИХОЛОГИЧЕСКАЯ ГОТОВНОСТЬ К ВЗАИМОДЕЙСТВИЮ С ОБРАЗОВАТЕЛЬНОЙ СРЕДОЙ ВУЗА У ПЕРВОКУРСНИКОВ И ИХ ПСИХИЧЕСКОЕ СОСТОЯНИЕ В ПЕРИОД АДАПТАЦИИ
}

\section{PSYCHOLOGICAL READINESS TO INTERACT WITH THE EDUCATIONAL ENVIRONMENT OF THE UNIVERSITY FOR FIRST-YEAR STUDENTS AND THEIR MENTAL STATE DURING THE ADAPTATION PERIOD}

S. Afanasieva P. Alekseyeva

Summary:The period of adaptation to the conditions of higher education is characterized by changes in the social status, role, situation, characteristics of the leading type of activity of the individual. Consequently, the characteristic features of first-year students ' abilities to respond to the influences and expectations of the educational environment and their subjects are revealed. The formation of these abilities contributes to successful and most effective adaptation, which can be reflected in high academic performance, active life position, satisfaction with the situation of obtaining professional education and the qualitative development of professional competence among students. The study involved first-year students of 2 divisions of NEFU. The study showed that psychological readiness to interact with the educational environment affects the mental state of subjects of the educational environment during the adaptation period. The most significant component is the cognitive readiness to interact with the educational environment. students with a high level of cognitive readiness to interact with the educational environment may have low frustration resistance and low rigidity, but a pronounced tendency to high anxiety.

Keywords: psychological readiness to interact with the educational environment of the University, socio-psychological, emotional, personal readiness, mental States, adaptation period.

\section{Введение}

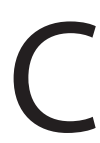

егодня, получение качественного образования, умение критически и творчески мыслить, вести социально адаптивный, здоровый образ жизни становятся ведущими ценностями среди всех групп населения. Ожидания вчерашних выпускников школ и реальность образовательной среды ВУЗа не всегда могут совпадать. Во многих исследованиях, посвященных адаптации первокурсника к условиям образовательной организации, делают акцент на психоэмоциональную
Афанасьева Снежана Михайловна

ФГАОУ ВО «Северо-Восточный федеральный университет им. М.К. Аммосова», г. Якутск

tottoros98@mail.ru

Алексеева Полина Степановна

Дочент, ФГАОУ ВО «Северо-Восточный федеральный университет им. М.К. Аммосова», г. Якутск alinava@inbox.ru

Аннотация: Период адаптации к условиям высшего учебного заведения характеризуется с изменениями социального статуса, роли, ситуации, характеристик ведущего вида деятельности индивида. Следовательно, проявляются характерные особенности способностей первокурсников реагировать на воздействия, ожидания образовательной среды и их субъектов. Сформированность данных способностей способствуют успешную и наиболее эффективную адаптацию, которые могут отражаться в высокой академической успеваемости, активной жизненной позиции, удовлетворенности ситуацией получения профессионального образования и на качественное освоение профессиональной компетенции у студентов. В проведенном исследовании участвовали студенты первокурсники 2х подразделений СВФУ. Проведенное исследование показало психологическая готовность к взаимодействию с образовательной средой влияет на психическое состояние субъектов образовательной среды в период адаптации. Наиболее значимым компонентом является когнитивная готовность к взаимодействию с образовательной средой. у студентов с высоким уровнем когнитивной готовности к взаимодействию с образовательной средой может наблюдаться низкая фрустрационная устойчивость и низкая ригидность, но выраженная склонность к высокой тревожности.

Ключевые слова: психологическая готовность к взаимодействию с образовательной средой ВУЗа, социально-психологическая, эмоциональная, личностная готовность, психические состояния, адаптационный период.

сферу личности, отводя ей роль отражения начальных изменений личности, т.е. считают, что психические состояния первичны по-своему проявлению к изменениям, а остальные показатели вторичны, следовательно, показатели эмоциональной сферы отражают какие изменения происходят у индивида в заданном промежутке времени.

Поэтому, становится важным рассмотрение основ для выявления специфики влияния психологической готовности на психическое состояние первокурсников в образовательной системе ВУЗа. 
Необходимость исследования проблемы влияния психологической готовности на психическое состояние первокурсников в адаптационный период к образовательной среде ВУЗа заключается в том, что на данном этапе происходит изменение социальной роли субъекта, а также появление новых воздействий, задаваемых требований и ожиданий, поэтому в новой среде индивид использует свои «внутренние ресурсы», которые могут способствовать для более или менее эффективной адаптации. Следовательно, необходимо изучить «внутренние ресурсы», которые выступают в данном исследовании в роли психологической готовности (эмоциональный, личностный, когнитивный, социально-психологический компоненты) и проследить их связь с психо-эмоциональным состоянием индивида, т.к. оно по своей природе отражает начальные изменения аспектов личности, которые помогут выявить сформированность внутренних ресурсов.

Нами было сформулировано предположение о том, что психические состояния студентов в период адаптации будут иметь различия в зависимости от уровня сформированности компонентов психологической готовности

\section{Основная часть}

Поведение выстраивается из взаимодействия двух объектов - среды и индивида. Процесс адаптации затрагивает различные сферы жизнедеятельности человека, которые тесно между собой взаимосвязаны (биологический, физиологический, социальный, психологический, психический, сенсорный, профессиональный уровень), поэтому «адаптация» как предмет изучения рассматривается и в философии, психологии, социологии, медицине, педагогике и мн.др. науках.

В работах К.Г. Юнга, главной функцией структуры сознания считается адаптация. Категория адаптации им определяется как более широкое понятие чем «познание», так как, с его точки зрения, адаптация может реализоваться не только в виде познавательной деятельности. Понятие адаптации позволяет лучше постичь природу человека и специфику его взаимодействия с миром. $[11$, c. 59].

Если рассмотреть физиологический уровень адаптации, исходя из работ У. Кэннона, то организм стремится сохранить баланс уровня гомеостаза при любых внешних воздействиях. Любые внешние воздействия влияют на систему организма, тем самым вызывая изменения, которые не являются отклонениями от нормы. Но при длительном воздействии стимулов, где применяются неэффективные формы стратегий, то организм истощается, проявляя различные психосоматические заболевания и т.д. [5]

В отечественной науке явление адаптации изучается как биологическое приспособление к среде (Е.А. Горелова, В.И. Медведев), как процесс активного взаимодействия субъекта и среды (П.К. Анохин, Ф.Б. Березин), как совокупность процесса и результата приспособления (К.А. Абульханова-Славская, А.Б. Георгиевский), и как механизм развития личности (А.А. Реан, А.А. Алдашева).

В концепции Ф.Б. Березина психическая адаптация является процессом установления равновесных взаимодействий между психикой и средой, является комплексным феноменом, который не сводится к психологической адаптации [2]. Психическая адаптация является процессом установления адекватных взаимоотношений между психической деятельностью, обуславливающей поведение, и физиологическими механизмами, обеспечивающими реализацию поведения. В основе концепции Ф.Б. Березина, была предложена трехкомпонентная модель психической адаптации как системы, обеспечивающей:

1. оптимальное соотношение между психическими и физиологическими адаптационными процессами (психофизиологическая адаптация);

2. сохранение психического гомеостаза и устойчивого целенаправленного поведения (собственно психическая адаптация);

3. адекватное взаимодействие с социальным окружением (социально-психологическая адаптация) [2].

В работах А.А. Северного и Н.М. Иовчука утверждают, что психический адаптационный процесс рассматривает изменение стереотипа личности и его состояния с требованиями внешней среды. А дезадаптация представляет собой нарушенное взаимодействие субъекта с окружающей средой, которое обуславливается невозможностью выполнить требуемые задачи в соответствии социальной роли, возможностям индивида [8]. В.Я. Семке отмечает, что изменение состояния эмоциональной сферы может быть связано с непривычными новыми требованиями социальной роли субъекта, которые могут превосходить его внутренние ресурсы, тем самым вызывая у индивида стресс-реакцию организма и психоэмоциональную неустойчивость (высокая тревожность, агрессивность, фрустрированность) [9].

Начало любой деятельности приводит к полной перестройка не только его ведущего типа деятельности и социальной роли, но отношений межличностных и социальных ролей. Для каждого человека любые изменения связаны с эмоциональной нагрузкой, переживанием стрессовых ситуаций, которые влияют на появление эмоциональных расстройств. Фундаментом таких откло- 
нений чаще всего лежит тревожность как устойчивое психическое образование. [10] Таким образом, адаптация человека может осуществляться на разных уровнях, находящихся в отношениях взаимосвязи и взаимовлияния и имеющих свою специфику мобилизации адаптационных ресурсов [6].

Ю. Колесников и Б. Рубин рассматривают адаптацию первокурсников как процесс вовлечения индивида в совокупность форм деятельности и ролей, акцентируя на процесс творческого приспособления субъекта к особенностям выбранной профессии. Таким образом, адаптация студента - это положительное отношение к особенностям профессии, академическая успеваемость, психоэмоциональная устойчивость. [7]

Анализируя концепции можно сказать, что психическое состояние напрямую взаимосвязана с активностью или пассивностью в период адаптации, которая тесно связана с психологической готовностью к взаимодействию с образовательной средой ВУЗа.

С.Н. Кусакина выделяет три компонента к вузовскому обучению. Мотивационно-профессиональный компонент, который предполагает желание и стремление учиться, выполнять задаваемые требования и обязанности ВУЗа, осознанность и самостоятельность выбора профессии. Далее когнитивно-темповый компонент имеет два подвида: интеллектуальный и организационно-темповый. Интеллектуальный компонент включает в себе средний показатель интеллектуального развития и уровень подготовки школьной программы. Организационно-темповый компонент отражает навыки чтения, письма, работы с текстом и скорость переключения внимания. Волевой компонент отражает навыки саморегуляции поведения и самоорганизации [3].

В работах О.Н. Локатковой психологическая готовность к взаимодействию с образовательной средой ВУЗа включает 4 компонента, которые содействуют принятию учебно-профессиональных целей в соответствии с требованиями образовательной среды [4]. Она утверждает, что динамика психологической готовности зависит от сформированности данных четырех компонентов, идеальная картина адаптированности студента отражает: эмоциональный компонент - повышенное эмоциональное благополучие (отсутствие негативных эмоций, низкая тревожность), положительное эмоциональное состояние при посещении пар; когнитивный компонент - активная познавательная деятельность, повышенная скорость усвоения тем учебного материала и их эффективное применение, академическая успеваемость; личностный компонент - позитивная Я-концепция, низкая личностная тревожность, адекватность уровня самооценки и притязаний. Данные внутренние ресурсы об- учающегося позволяют эффективно использовать их в процессе обучения, в формировании положительной учебной мотивации, в построении оптимизированных межличностных отношений с субъектами образовательной среды, в сформированности умений и навыков коммуникации (выступать перед публикой, высказывать свое мнение и т.д.), в низких показателях межличностных конфликтов, активной общественной жизни [4].

Адаптационный период связан с эмоциональной нагрузкой, переживанием стрессовых ситуаций, может усиливаться тревожность как устойчивое психическое образование.

\section{Материалы и методы исследования}

В исследовании приняли участие академические группы студентов -первокурсников двух подразделений СВФУ им. М.К. Аммосова, в возрасте от 17 до 22 лет, общее количество составило 75 человек.

Были использованы следующие методики исследования:

- «Самооценка психических состояний» (Айзенк Г.)данная методика позволяет выявить выраженность следующих психических состояний индивида: тревожность; фрустрация; агрессивность; ригидность.

- «Диагностика психологической готовности» (Локаткова О.Н.)-выявляет особенности психологической готовности по четырем критериям: эмоциональный, личностный, когнитивный, социально-психологический.

Статистическая обработка и оценка достоверности результатов проводилась с использованием программы SPSS 22.0 для персональных компьютеров и пакета прикладных программ Microsoft Office. Выявления связи между психическими состояниями и психологической готовности к взаимодействию с образовательной средой проводилось с помощью коэффициента корреляции Пирсона (r-Пирсона)

\section{Представление результатов изучения психического состояния студентов в перио $\Delta$ ахаптации}

Изучение психического состояния студентов проводилось в сентябре-октябре месяце первого учебного года студентов. Адаптация в легкой форме, как правило, длится два месяца, к концу октября происходит освоение нового статуса студента и новых требований Вузовской среды.

Результаты измерения уровней психического состояния отражены на рисунке 1. 


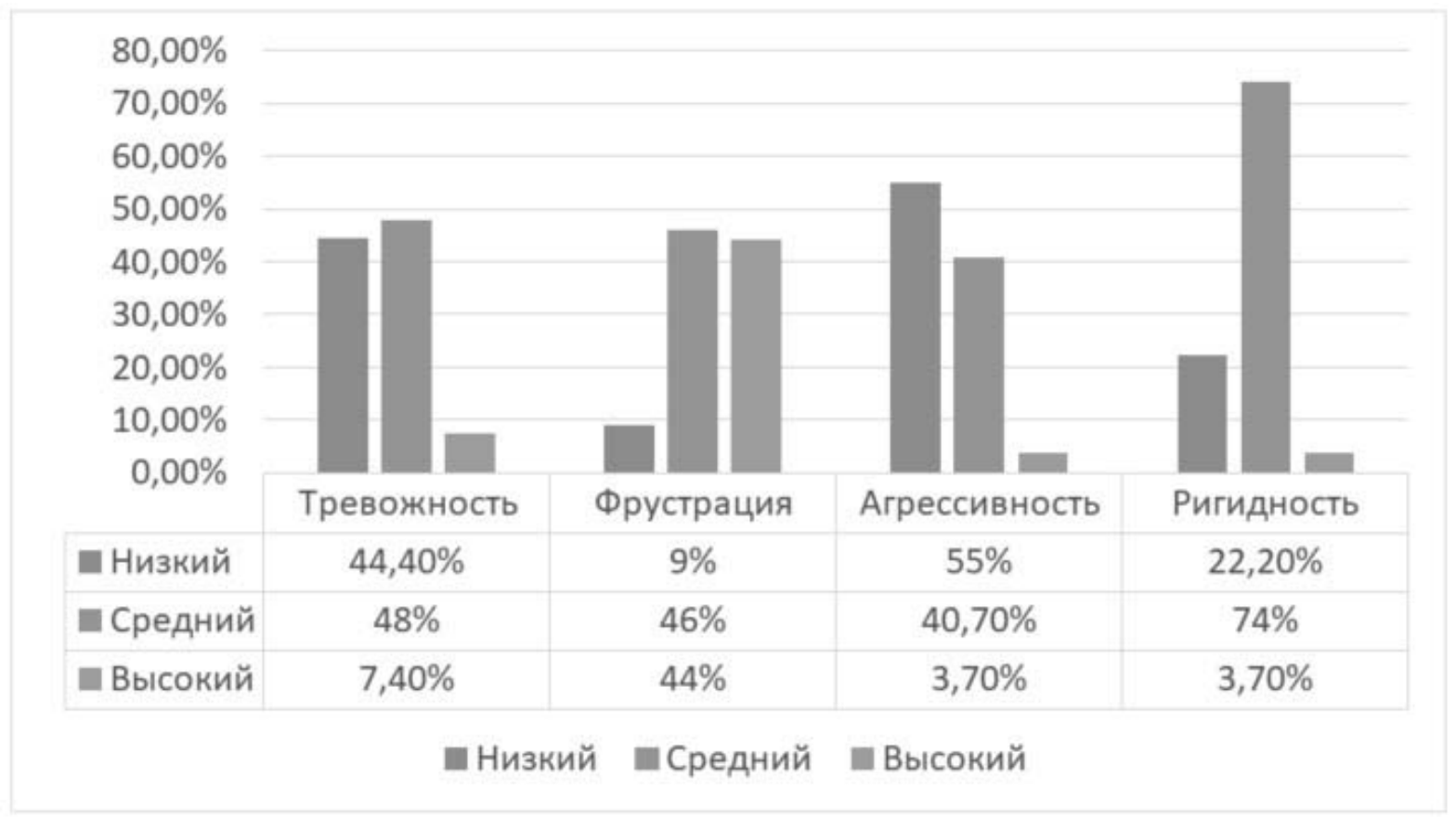

Рис. 1. Результаты измерения психических состояний

Полученные результаты свидетельствуют о том, что преобладающим является средний уровень выраженности тревожности, фрустрации, агрессивности и ригидности.

У 48 \% показатель «тревожности» представлен в среднем уровне 8,2, следовательно, наблюдается склонность к ожиданию негативного развития событий, неудач в решении различных задач, возникновение предположения трагических исходов ситуаций. Но у 44,4\% низкая тревожность, которая возможно говорит о том, что им свойственна сдержанность чувств и слабая эмоциональная вовлеченность в различных жизненных ситуациях.

По критерию «фрустрация» преобладает средний уровень, то есть первокурсники в состоянии регулировать и перенаправлять свое сознание от тревожащих мыслей, могут придавать событиям меньшую ценность, но это может привести к накоплению дел и т.д. У 44\% выражена высокая фрустрированность, соответственно, для у первокурсников преобладают иррациональные убеждения, которые акцентируют боязнь неудач, избегание трудностей. У 9 \% первокурсников низкая фрустрированность, т.е. у них высокая самооценка, устойчивость к неудачам, но характерна переоценка значимость необходимых ситуаций, событий, которое может привести к низкой академической успеваемости.

По критерию «агрессивность» у большинства 55\% низкий показатель, который отражает низкую враждебность по отношению к кому-либо или чему-либо и сохранение спокойствия при каких-либо ситуациях.
Показатель у преобладающего количества студентов - 74\% уровень «ригидности» средний, возможно это связано с трудностями менять привычки, настороженным отношением ко всему новому и во взаимодействии со сверстниками и преподавателями. У меньшинства-3,7\% низкая высокая ригидность, следовательно, их трудно переубедить, неизменность поведения и взглядов.

На рисунке 2 отражены результаты по определению уровня выраженности компонентов психологической готовности студентов.

Полученные нами результаты говорят о том, что для выборки первокурсников характерен средний уровень сформированности психологической готовности к взаимодействию с образовательной средой ВУЗа. Студенты первых курсов проявляют адекватность эмоциональных реакций на определенные стимулы, но иногда может выражаться впечатлительность и импульсивность. Для респондентов характерна объективная оценка своих возможностей учебных и творческих, могут осуществлять самоконтроль и эффективно выполнить задаваемые задания, но возможна отсутствие положительной мотивации учебной деятельности, то есть негативные установки на академическую успеваемость. Большинство первокурсников могут легко устанавливать контакт и поддержать беседу, но в определенный момент не могут найти общий язык с кем-либо, могут проявить конфликтность. Установки на моральную нормативность к взаимодействию с образовательной средой и социально-психологическую адаптацию к условиям образова- 


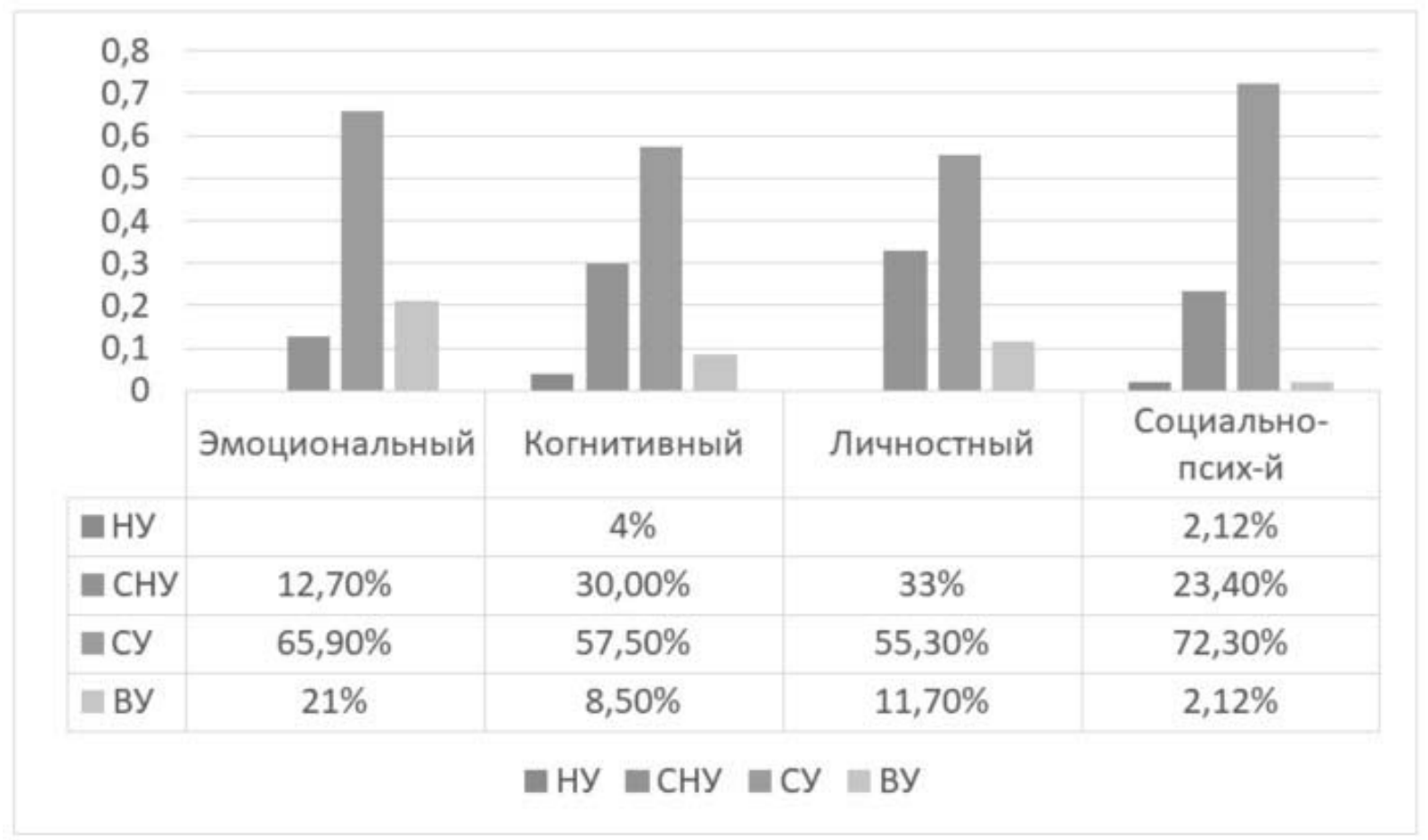

Рис. 2. Распределение компонентов психологической готовности по уровням

тельной среды учебного заведения нейтральны.

Характеристика эмоционального компонента психологической готовности к взаимодействию со средой ВУЗа, показывает, что у студентов первого курса отсутствуют лица с несформированными стратегиями регуляции эмоции. Средние показатели с тенденцией к низкому уровню эмоциональной готовности демонстрируют $12,7 \%$ - их неуверенность в себе, тревожность могут привести к ухудшению академических результатов и дезорганизации деятельности. Но у $21 \%$ студентов высокий уровень, следовательно, у них сформированы стратегии регуляции эмоции, которые способствуют снижению уровня тревожности, фрустрации и т.д.

Низкий уровень по когнитивному компоненту готовности выявлен у 4\% респондентов. Таким образом, меньшинство принижают свои творческие и учебные возможности, а также навыки, которые способствуют для более эффективного выполнения поставленных учебных задач или у них отсутствуют или слабо развиты навыки, которые могут помочь для более отбирать необходимую информацию и т.д. У $30 \%$ обследованных констатируем средний когнитивный уровень с тенденцией к низкому значению, об этом можно предположить, что учебный материал запоминается не полно, возможно изза механического способа запоминания материала, недостаточная речевая подготовка, которое способствуют к трудностям при высказывании своего мнения и препятствий при выполнении какого-либо задания.
Развитие личностного компонента у 33\% в исследуемой выборке студентов на среднем уровне с тенденцией к низкой личностной готовности к взаимодействию с образовательной средой. Это может говорить о том, что присутствует страх, склонность непрерывно обдумывать тревожащие мысли и образы, о нерешительности, робости, тревоге. Не зафиксированы низкие результаты у студентов, т.е. студенты - первокурсники способны к рефлексии и «Я-образ» первокурсника достаточно устойчивый.

23,4\% опрошенных первокурсников показывают средний уровень социально-психологической готовности к взаимодействию с образовательной средой ВУЗа с тенденцией к низкому. Это может говорить о низком социальном статусе, характеризующийся узким кругом общения и малым количеством знакомых, трудностями в общении и наличием чувства неуверенности при знакомстве с новыми людьми и в принятии новой социальной роли. Возможно, основой для развития этих свойств стала низкая коммуникативная способность.

Согласно, исследованию Локатковой Н., средний с тенденцией к низкому уровень личностного компонента во взаимодействии с образовательной средой характеризуется неосознанным выбором направления обучения, ориентированностью на социальное мнение (мода, престижность профессии в обществ), на высокооплачиваемость, получение определенных материальных благ и т.п. Поэтому, для студентов с низким уровнем личностного компонента во взаимодействии с образовательной 
средой ВУЗа наблюдается несформированность планов на будущее, неопределенность и несоответствие выбранного вуза интересам самого студента, что в конечном счете, снижает мотивированность в учебной деятельности и ее ценность не связывают с собственной личностью

\section{Обсужление результатов исслеАования.}

С помощью коэффициента корреляции Пирсона выявили наличие связи между показателями психического состояния и компонентами психологической готовности. Результаты отражены в таблице №1:

Таблица 1. Корреляционная плеяда сформированности психологической готовности и психического состояния

\begin{tabular}{|l|l|l|l|}
\hline Показатели & Эмоциональный & $\begin{array}{l}\text { Социально-пси- } \\
\text { холический }\end{array}$ & Когнитивный \\
\hline Тревожность &,$- 306^{* *}$ & - &,$- 490^{* *}$ \\
\hline Фрустрация &,$- 416^{* *}$ & - &,$- 579^{* *}$ \\
\hline Агрессивность &,- 026 &, $408^{* *}$ & - \\
\hline Ригидность &,$- 380^{* *}$ &,$- 379^{* *}$ &,$- 528^{* *}$ \\
\hline
\end{tabular}

По результатам анализа наблюдается отрицательная корреляционная связь на высоком уровне значимости с фрустрацией $\left(r=-0,579^{* *}, p=0,01\right)$ и связь с ригидностью $\left(r=-0,528^{* *}, p=0,01\right)$, а также с тревожностью $\left(r=-0,490^{* *}\right.$, $\mathrm{p}=0,01)$. То есть, мы можем утверждать, что у студентов c высоким уровнем когнитивной готовности к взаимодействию с образовательной средой может наблюдаться низкая фрустрационная устойчивость и низкая ригидность, но выраженная склонность к высокой тревожности, т.е. если уровень подготовленности высокий, соответственно, уровень тревожности возрастает, так как возникает иллюзорная картина упущенности важных моментов по определенной теме. В исследуемой выборке, установлен средний уровень сформированности психологической готовности к взаимодействию с образовательной средой ВУЗа. У $65 \%$ студентов адекватность эмоциональных реакций на определенные стимулы, но иногда может выражаться впечатлительность и импульсивность. В когнитивном компоненте у респондентов (57\%) характерна объективная оценка своих возможностей учебных и творческих, могут осуществлять самоконтроль и эффективно выполнить задаваемые задания, но возможна отсутствие положительной мотивации учебной деятельности, то есть негативные установки на академическую успеваемость. В личностном компоненте отразилось, что большинство респондентов 55\% могут легко устанавливать контакт и поддержать беседу, но в определенный момент не могут найти общий язык с кем-либо, могут проявить конфликтность. Социально- психологический компонент: установки на моральную нормативность к взаимодействию с образовательной средой и социально-психологическую адаптацию к условиям образовательной среды учебного заведения нейтральны.

Результаты исследования психических состояний показывают, что преобладающим является средний уровень выраженности. Показатель «тревожности»у большинства наблюдается склонность к ожиданию негативного развития событий, неудач в решении различных задач, возникновение предположения трагических исходов ситуаций. По критерию «фрустрация» выяснилось, что большинство 46\% регулируют и перенаправляют свое сознание от тревожащих мыслей, могут придавать событиям меньшую ценность, но это может привести к накоплению дел и т.д. По критерию «агрессивность» у большинства 55\% низкий показатель, который отражает низкую враждебность по отношению к кому-либо или чему-либо и сохранение спокойствия при каких-либо ситуациях. Показатель у преобладающего количества студентов- 74\% уровень «ригидности» средний, возможно это связано с трудностями менять привычки, настороженным отношением ко всему новому и во взаимодействии со сверстниками и преподавателями [1].

\section{Bыво}

Таким образом, психологическая готовность к взаимодействию с образовательной средой влияет на психическое состояние субъектов образовательной среды в период адаптации. Наиболее значимым компонентом является когнитивная готовность к взаимодействию с образовательной средой. Наблюдается отрицательная корреляционная связь на высоком уровне значимости с фрустрацией $(r=-0,568, p=0,01)$ и связь с ригидностью $\left(r=-0,528^{* *}, p=0,01\right)$, а также с тревожностью $\left(r=-0,490^{* *}\right.$, $\mathrm{p}=0,01)$. То есть, мы можем утверждать, что у студентов c высоким уровнем когнитивной готовности к взаимодействию с образовательной средой может наблюдаться низкая фрустрационная устойчивость и низкая ригидность, но выраженная склонность к высокой тревожности.

Динамика психологической готовности зависит от сформированности данных четырех компонентов, картина адаптированности студента отражает эмоциональную, активную познавательную деятельность, повышенную скорость усвоения тем учебного материала и их эффективное применение, академическую успеваемость, низкую личностную тревожность, адекватность уровня самооценки и притязаний, оптимизированные межличностные отношения с субъектами, отсутствие конфликтов, сформированность умений и навыков коммуникации. 


\section{ЛИТЕРАТУРА}

1. Афанасьева С.М. Психическое состояние первокурсников в период адаптации к образовательной среде вуза//Психология : Материалы 57-й Междунар. науч. студ. конф. 14-19 апреля 2019 г. / Новосиб. гос. ун-т. — Новосибирск: ИПЦ, НГУ, 2019. — 58 с.

2. Березин Ф.Б. Психическая и психофизиологическая адаптация человека. - Л.: Наука, 1988. - 267 с.

3. Кусакина С.Н. Проблема готовности к обучению в Вузе в отечественной психологии. Казань: ЗАО «Новое знание», 2007.-С.43-46

4. Локаткова 0.Н. Регрессионный анализ компонентов психологической готовности студентов-первокурсников к взаимодействию с образовательной средой вуза [Текст] / 0.Н. Локаткова // Молодой ученый. — 2014. — №16. — С. 390-393.— 0,4 п.л.

5. Меерсон Ф.3. Физиология адаптационных процессов. - М.: Наука, 1986. -635

6. Налчаджян А.А. Психологическая адаптация: механизмы и стратегии / А.А. Налчаджян. 2-е изд., перераб. и доп. - М.: Эксмо, 2010. - 368 с.].

7. Савельева Н.Г. Дезадаптация учащейся молодежи как одна из наиболее актуальных проблем отечественной психологии и педагогики //- Социальная и специальная педагогика: 2011.-С. 79.

8. Северный А.А., Иовчук Н.М. Междисциплинарное взаимодействие в коррекционной работе при пограничной психической патологии // Ассоциация психиатров и психологов. - М.: 1995.-1-6С.

9. Семке В.Я. Психологическая модель травматического стресса // Научно-методический электронный журнал «Концепт». - 1999. - Т. 34. - С. 62-70.

10. Сергеева Б.В. Проблема тревожности в процессе адаптации // Научно-методический электронный журнал «Концепт». - 2017. - Т. 34. - С. 62-70.

11. Юнг К.Г. Проблемы души нашего времени. - М.: Прогресс, 1994. - 329 с. 59

(с) Афанасьева Снежана Михайловна (tottoros98@mail.ru), Алексеева Полина Степановна (alinava@inbox.ru)

Журнал «Современная наука: актуальные проблемы теории и практики»

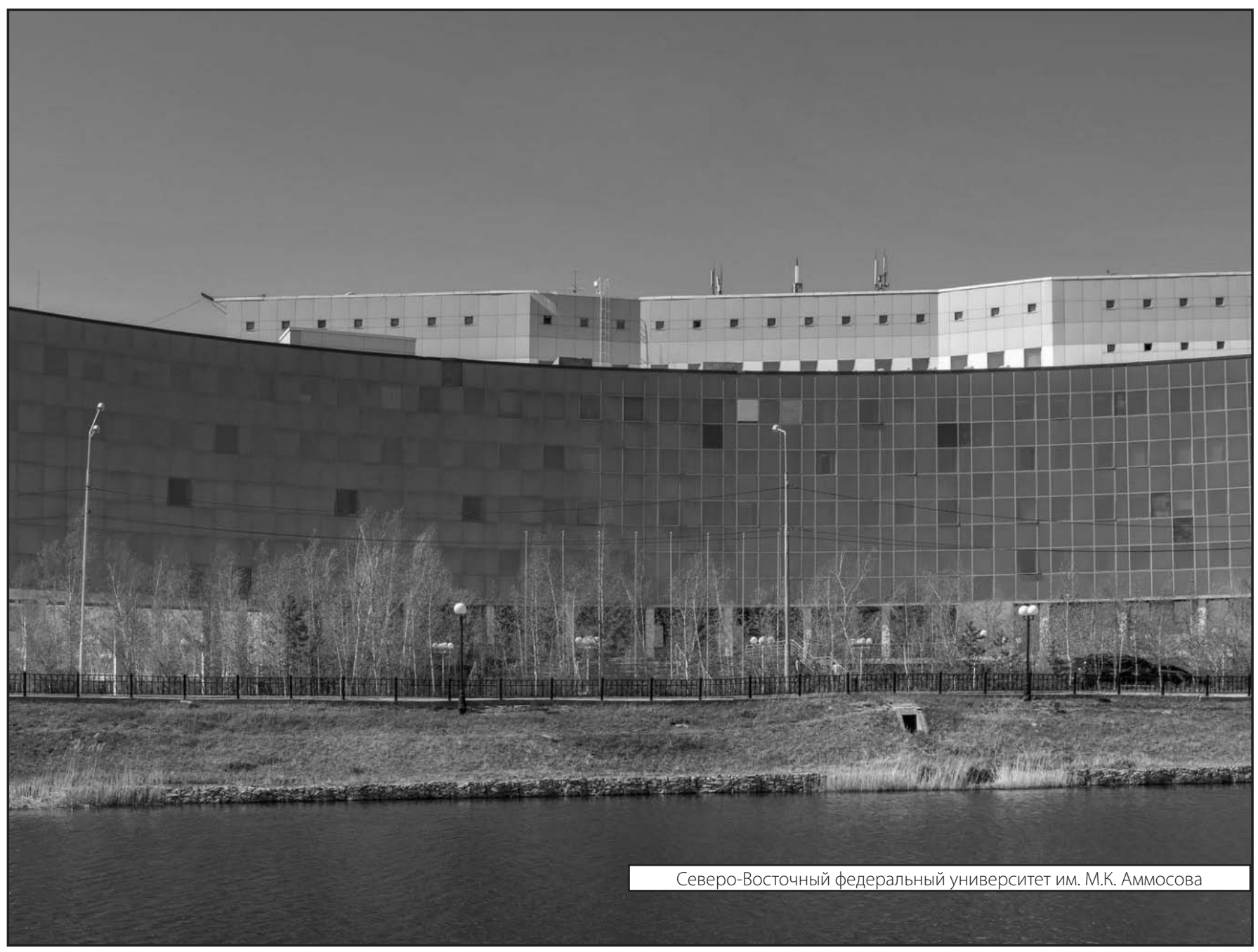

